\title{
Effects of Fungicide and Acetylsalicylic Acid Treatments on Qualitative and Quantitative Tomato Production
}

\author{
Ramona Aurelia HOROTAN ${ }^{1 *}$, Alexandru S. APAHIDEAN ${ }^{1)}$ \\ ${ }^{1)}$ Departament of Horticulture, University of Agricultural Sciences and Veterinary Medicine, Cluj- \\ Napoca \\ *)corresponding author, e-mail: aurahorotan@yahoo.com \\ BulletinUASVM Horticulture 72(1) / 2015 \\ Print ISSN 1843-5254, Electronic ISSN 1843-5394 \\ DOI:10.15835/buasvmcn-hort:10583
}

\begin{abstract}
By stimulating the plant defense system using acetylsalicylic acid, there were studied various physiological parameters and productivity of tomato crop in the field, compared to a tomato crop treated with systemic fungicides and a sustainable culture treated with $\mathrm{CuSO}_{4}$ (Bordeaux) mixture. Experimental crop was made up of two tomato varieties, the Sibiu local population and Buzău 50, both with undetermined growth and the used treatments were produced from: a systemic fungicides based mancozeb (60\%) and dimetomorph (9\%), contact fungicides - a mixture of $\mathrm{CuSO}_{4}$ (Bordeaux mixture) and acetylsalicylic acid. Thereby, it resulted six experimental variants located in three repetitions. Regular observations were made in the field, on the growth and development of vegetative organs, of inflorescences and fruits, quality and quantity production of tomatoes, depending on the variety and the used treatment. There were found significant differences in experimental physiology tomato crops. Buzău 50 variety crop, treated with aspirin significant increases number of leaves, flowers and fruits. Crop productivity of both tomato varieties treated with aspirin was significantly increased. The groups treated with aspirin had significantly higher production compared to groups treated with fungicide. Aspirin generates a normal growth and resistance to the fungal pathogens for tomatoes.
\end{abstract}

Keywords: acetylsalicylic acid, fungicides, Lycopersicon esculentum, plant physiology

\section{INTRODUCTION}

Solanum lycopersicum L. (Lycopersicon esculentum Mill.) is a herbaceous plant, vegetable, which naturally has a high food and therapeutic value. It originates from Peru where Aztecs cultivated it in the garden under the name "tomata". Tomatoes were brought to Europe by Spanish conquistadors as "Peruvian apple". Here they received it with reluctance and used it as ornamentals. Only at the end of XVIII century, tomatoes entered among food plant of great importance (Pârvu, 1991). The tomatoes have a differentiated tissues structure, with different chemical composition and physiological activity (Horotan and Oancea, 2013).

Tomatoes have a large variety of assortment. In the last years many varieties and hybrids have been introduced in agriculture, especially those with certain superior qualities, adapted to current environmental conditions. They are approved and listed in the "Official Catalogue of varieties of crop plants in Romania" (Indrea et al., 2012). Cultivated tomatoes belong to the genus Lycopersicon, subgenus Eulycopersicon, Esculentum (Mill.) species. There are many tomato species used in agriculture, especially those that are resistant to disease and the actions of certain environmental factors. Lycopersicon esculentum Mill. has many varieties of practical interest that can be determined or undetermined growth (Indrea et al., 2012).

Tomatoes are plant foods used for their nutritional value and therapeutic effects. Vegetable and fruits consumption stimulates body hydration, muscle activity, appetite, calcification, enzyme activity, defense ability, inhibits bacterial fermentation, metabolic regulation, and supplies essential amino acids (Suciu et al., 1987). The 
vitamins are indispensable for human body, which is unable to synthesize them. Many of these vitamins are taken from plants. Their deficiency to humans causes metabolism imbalances that will generate the appearance of specific diseases. With the development of medical research it was found the vitamins role as an antidote for different disorders of the human body, but also as a way of preventing the genetic disorders caused by the action of environment pollutants (Ciofu et al., 2004).

The fungicides were always in the attention of scientists. These, regardless of their origin, concentration or usage, are toxic both for the environment and human health, causing controversy and discussion worldwide for years (Horotan and Oancea, 2013). Some fungicides inhibit respiration in the mitochondria by blocking electron transport chain in complex III (cytochrome $\mathrm{bc}_{1}$ complex) (Venancio et al., 2003). Certain fungicides used to control Fusarium oxysporum are not very effective in controlling the disease and leave significant amounts of residue in tomato tissue. By increasing the dose, some fungicides cause inhibition of tomato plant growth (Amini and Sidovich, 2010). Tort et al (2005) reported that, regardless of the used dose, fungicides cause significant anatomical changes in tomato pollen. Also, high concentration of $\mathrm{Cu}$ application to soil and foliage, can adversely affect plant growth, fruit number and production of tomato (Sonmez et al., 2006). Fungicide often leads to serious environmental problems, including human health. Therefore it is necessary to minimize the chemicals used to control plant disease (Chourasiya et al., 2013).

Salicylic acid acts as a plant hormone that generates a positive impact on plant growth, photosynthesis, but mainly on the defense system of the plant. The acetyl group, for this acid does not change these characteristics in plants (Horotan and Oancea, 2013).

\section{MATERIALS AND METHODS}

To study the tomato physiology, two varieties were used: the Sibiu local population and Buzău 50. The experimental crop was placed in Șelimbăr, Sibiu county, 45 $46^{\prime} 48,9^{\prime \prime} \mathrm{N}$ latitude and $24^{\circ} 10^{\prime} 23,8^{\prime \prime}$ E longitude. The land has southern exposition, middle texture soil (sandy-loam) and 3\% humus content (Office of Pedological and Agrochemical Studies Sibiu). The crop was founded by seedlings produced in seedbeds and after 25 days were picked into $7 / 7 \mathrm{~cm}$ cubes. The seedlings have not been treated with any treatment (fertilizers, growth regulators, disinfectants). They were planted 60 days after emergence at $70-75 \mathrm{~cm} / 25$ - $30 \mathrm{~cm}$ distance, to $50 \mathrm{~m}^{2}$ area.

Three experimental tomato groups of each variety were formed: the group treated with pesticides (LP), the group treated in sustainable agriculture system (LS) and the group treated with acetylsalicylic acid solution (LA). Every group contains a total of 10 plants, on which was tested a treatment (technological factor). Tomatoes experimental crop consists of three repetitions. From the two tomato varieties, 6 experimental variants located in 3 replicates resulted. Technological factors used in this experiment, are commonly used in current agriculture, respectively chemical treatments: systemic fungicide based mancozeb (60\%) and dimethomorph (9\%) EU approved pesticides (TP) and contact fungicides based $\mathrm{CuSO}_{4}$ (Bordeaux) mixture used in sustainable agriculture (TS); Treatment with acetylsalicylic acid (aspirin), original treatment proposed to replace other treatments (TA).

Regular observations were made in the field, on the growth and development of vegetative organs, of inflorescences and fruits of each variety and treatment. Quality and quantity production of tomatoes was monitored at harvest time, depending on the variety and the treatment used.

Growth parameters of vegetative organs - stem / leaf - were measured at intervals of 30 days. The same time interval was used for observation and determination of multiple physiological parameters: number of leaves, inflorescences and flowers in inflorescence, number of fruits.

Early harvesting began in July to late August and late harvesting was completed in October. Each collection has been weighed in kilograms ( $\mathrm{kg})$, production / lot / repetition.

\section{RESULTS}

Height growth of tomato treated with three types of treatment varies from a physiological point of view. 60 days after planting, significant and very significant height increase of the variety Buzau 50 were found in tomatoes sprinkled with acetylsalicylic acid (TA) and contact fungicides (TS), respectively over $35 \%$ to those sprinkled with TA and over $75 \%$ to the tomatoes sprinkled with TS, compared to the control group (TP). However, 90 days after planting in the field, tomatoes of the variety Buzau 50 sprinkled with systemic fungicide (TP) (considered as control 
group) showed a slight height increase compared with those sprinkled with TA and TS (below 10\%) (fig.1).

Significant decrease of tomato flowering of the variety Sibiu local population were found in tomatoes sprinkled with acetylsalicylic acid (TA) and contact fungicides (TS). The tomatoes of variety Buzău-50 sprinkled with TA and TS showed a higher number of inflorescences compared to the control group (TP). (fig.2).
In the first decade of August (60 days) it has been observed that the number of fruits of the local population has not showed significant differences between treatments. During the same period, very significant fruit number increase at the variety Buzau 50 was found in tomatoes sprinkled with acetylsalicylic acid (TA) and contact fungicides - $\mathrm{CuSO}_{4}$ (Bordeaux) mixture (TS) compared to the control group (TP). In September (90 days), Buzău-50 tomato variety sprinkled with TA and TS

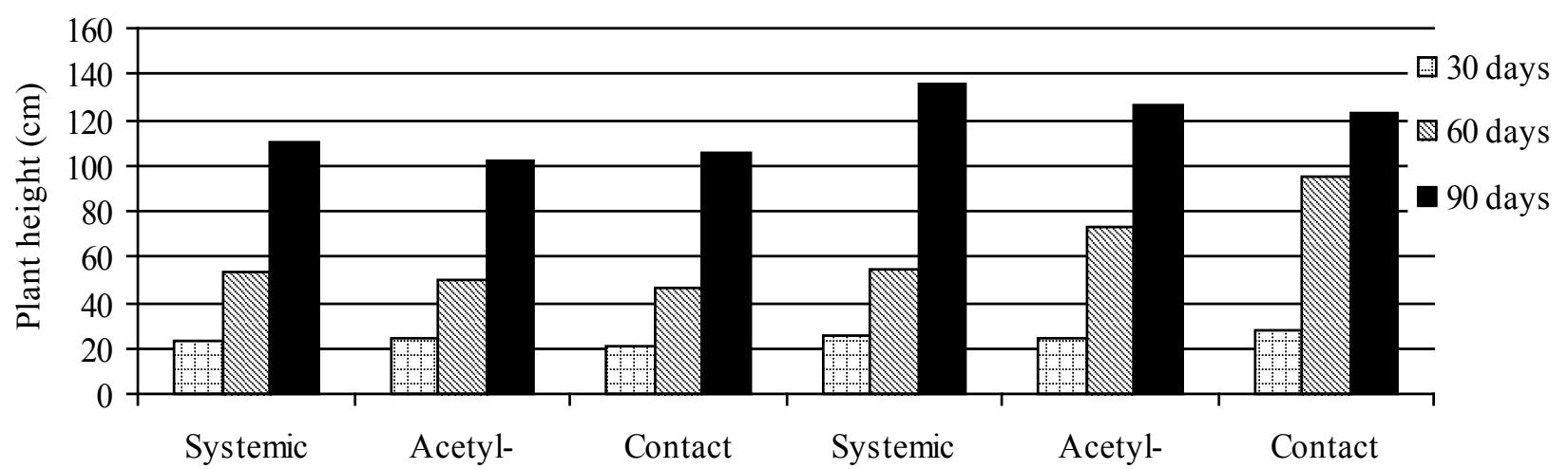

fungicide (TP) salicylic acid fungicide (TS) fungicide (TP) salicylic acid fungicide (TS)

(TA)

(TA)

Local population of Sibiu

Fig.1. Height growth of two tomato varieties treated with fungicides and acetylsalicylic acid (summer 2013)

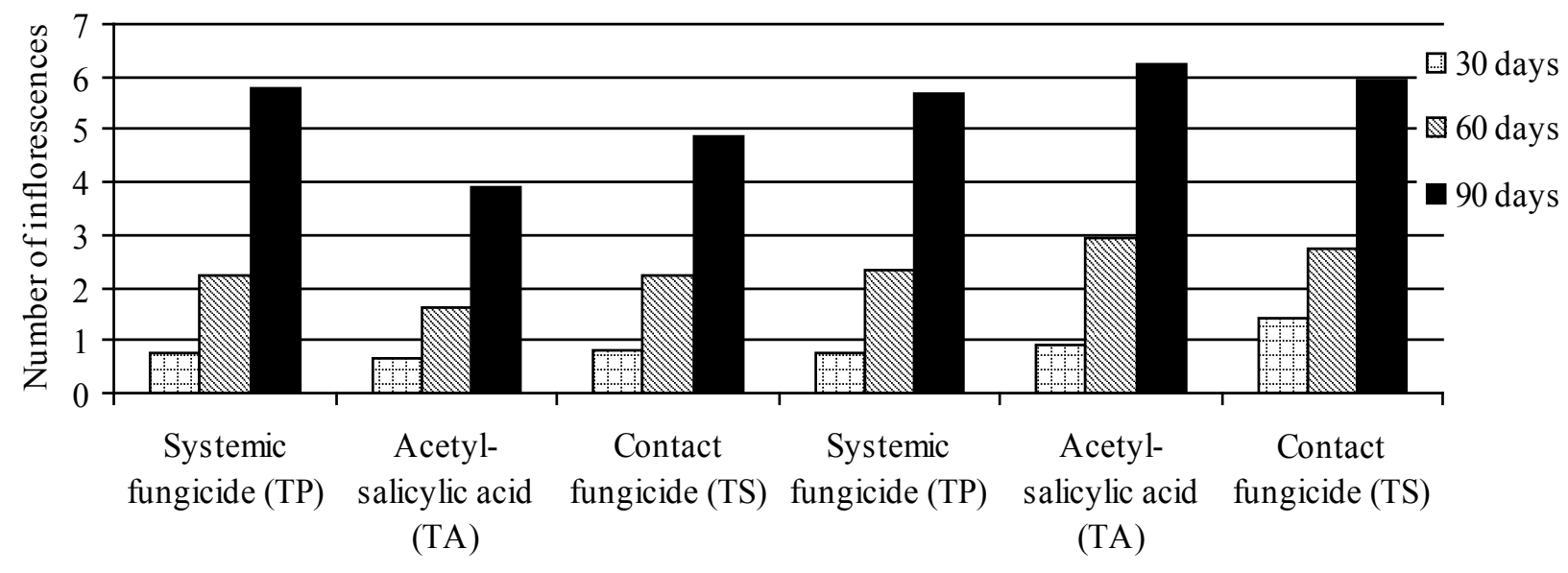

Local population of Sibiu

Buzău 50

Fig.2. Number of inflorescences of two tomato varieties, treated with fungicides and acetylsalicylic acid (summer 2013) 


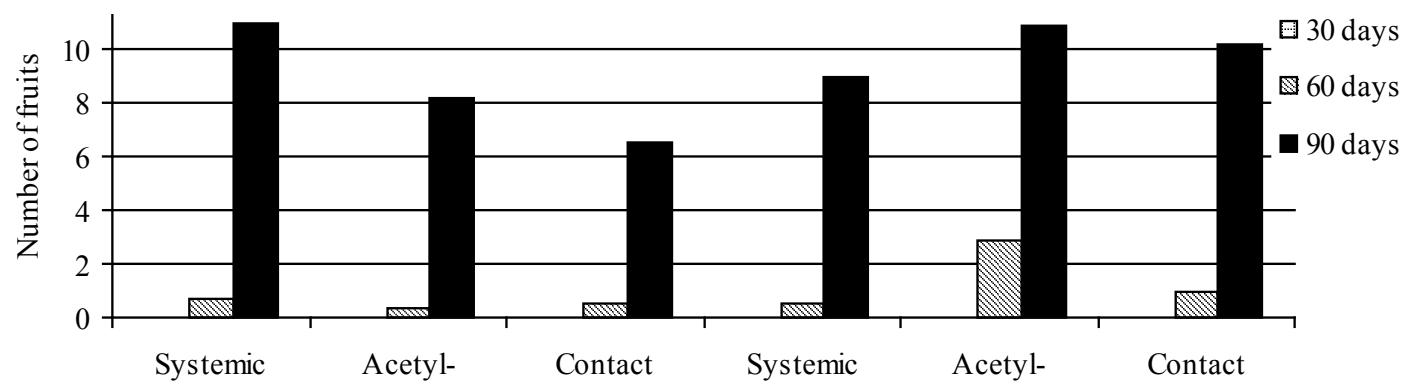

fungicide (TP) salicylic acid fungicide (TS) fungicide (TP) salicylic acid fungicide (TS)

(TA)

(TA)

Local population of Sibiu

Buzău 50

Fig.3. Number of fruits of two tomato varieties, treated with fungicides and acetylsalicylic acid (summer 2013)

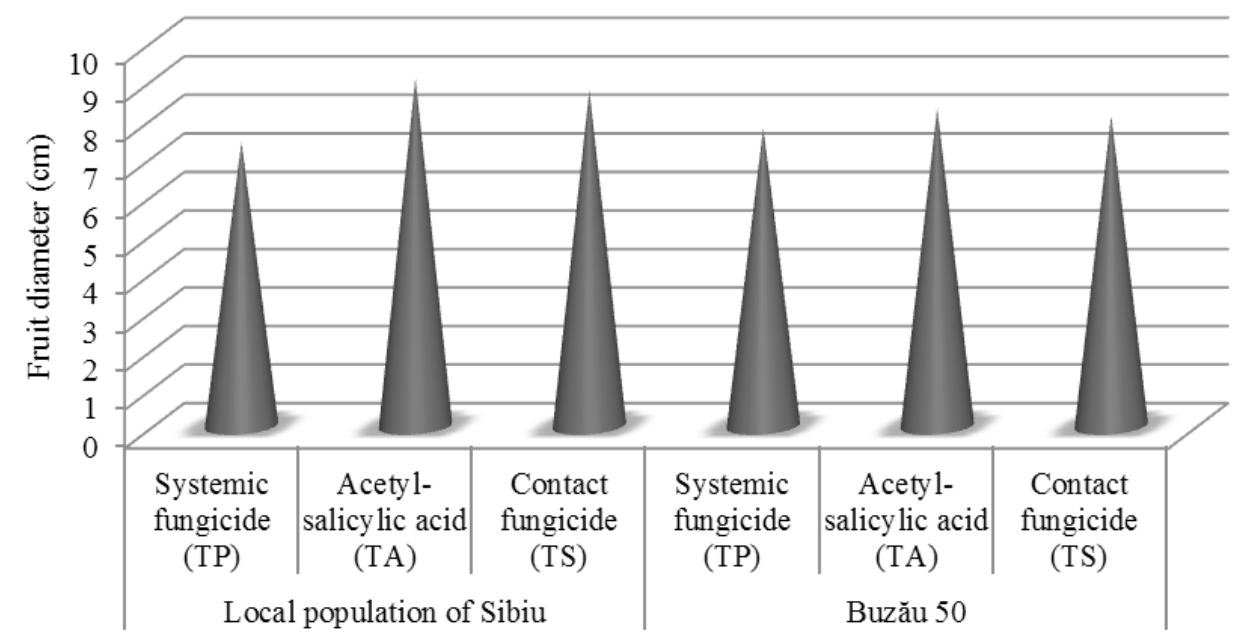

Fig.4. Fruit diameter (cm) of two tomato varieties, treated with fungicides and acetylsalicylic acid (summer 2013)

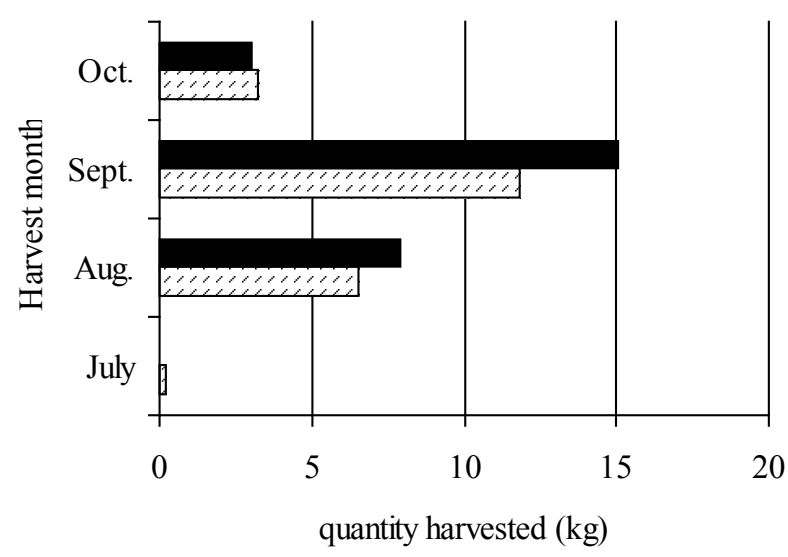

BUZĂU 50

$\square$ Local population of Sibiu

Fig.5. Dynamics of tomato production $\left(\mathrm{kg} / \mathrm{m}^{2}\right)$ of two tomato varieties, harvested during July 2013 - October 2013 
had a significant increase in fruits, while tomatoes of the variety Sibiu local population showed a decrease, compared to the control group TP (fig.3).

Although fruit number of the local population variety was lower at tomatoes treated with acetylsalicylic acid and contact fungicides - Bordeaux mixture, fruit diameter and their weight were decisive for the production of tomato crop year 2013 (fig.4).

At the systemic fungicide treated variant (TP), tomato fruits harvest began in the last decade of July, respectively the first decade of August to the other variants and continued until the first decade of October. The largest volume of fruits was harvested in the third decade of August and the last two decades of September, for all experimental variants.
Generally, the Buzau-50 cultivar dynamics of production was much favorable compared with the Sibiu local population (fig.5).

Analyzing the influence of cultivar on tomato production it was found that early production ranged from $2.63 \mathrm{~kg} / \mathrm{m}^{2}$ at the variety Buzau 50 to $2.18 \mathrm{~kg} / \mathrm{m}^{2}$ in the local population, production difference being significantly negative.

The total production ranged from $8.8 \mathrm{~kg} / \mathrm{m}^{2}$ at the variety Buzau 50 to $7.69 \mathrm{~kg} / \mathrm{m}^{2}$ in the local population, the difference of production being 1.11 $\mathrm{kg} / \mathrm{m}^{2}$, significantly negative (fig.6).

The treatments performed for disease control had an influence on production levels achieved. Early production was between $2 \mathrm{~kg} / \mathrm{m}^{2}$ at the systemic

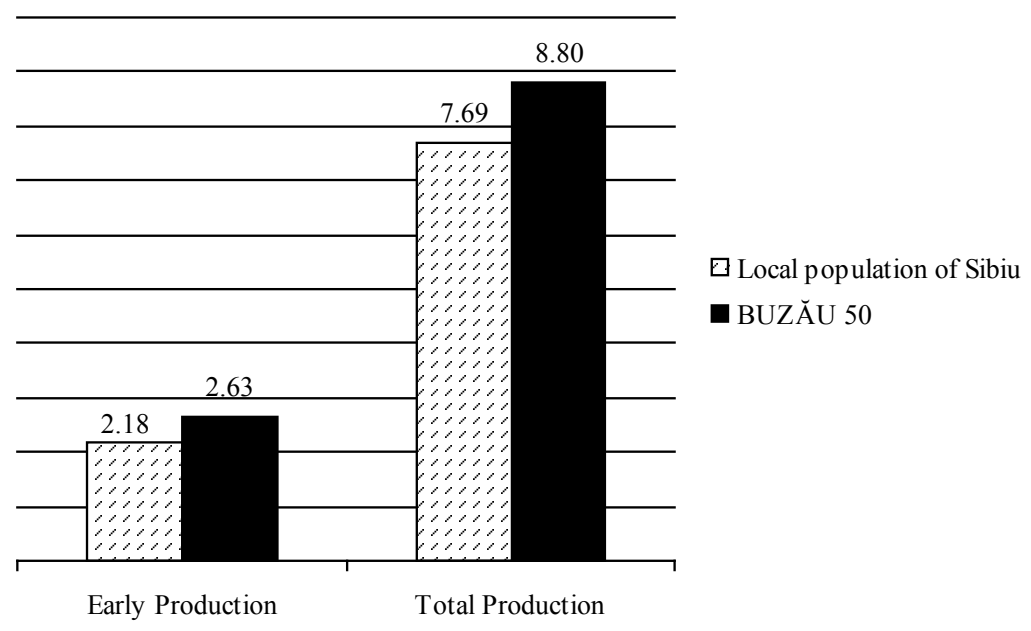

Fig.6. The cultivar influence on tomato early production (period of July-August 2013) and total production (period of July-October 2013), $\mathrm{kg} / \mathrm{m}^{2}$

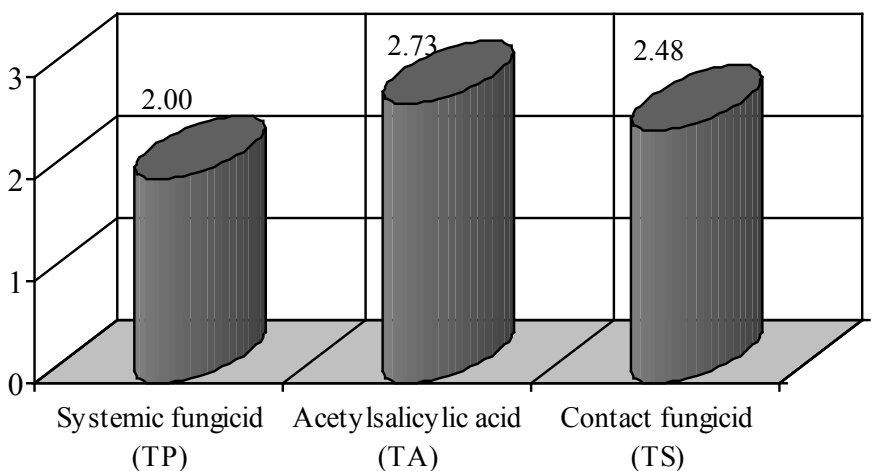

Fig.7. Treatment influence on early production of tomatoes (period of July-August 2013), $\mathrm{kg} / \mathrm{m}^{2}$ 
fungicide (TP) treated variant to $2.73 \mathrm{~kg} / \mathrm{m}^{2}$ at acetylsalicylic acid treated variant (TA). A production increase of $36.5 \%$ registered to the variant treated with acetylsalicylic acid solution, compared to the one treated with systemic fungicide, the production difference being very significant. Variant treated with contact fungicides - Bordeaux mixture showed a production increase of $23.7 \%$ compared to the control group, production difference being significant (fig.7).
Total production was between $7.59 \mathrm{~kg} / \mathrm{m}^{2}$ at the systemic fungicide treated variant (TP) to $9.22 \mathrm{~kg} / \mathrm{m}^{2}$ at acetylsalicylic acid treated variant (TA). A production increase of $21.4 \%$ registered to the variant treated with aspirin, compared to the one treated with systemic fungicide, the production difference being very significant. Variant treated with Bordeaux mixture (TS) showed a slight increase of $4.2 \%$, compared to the control group (fig.8).

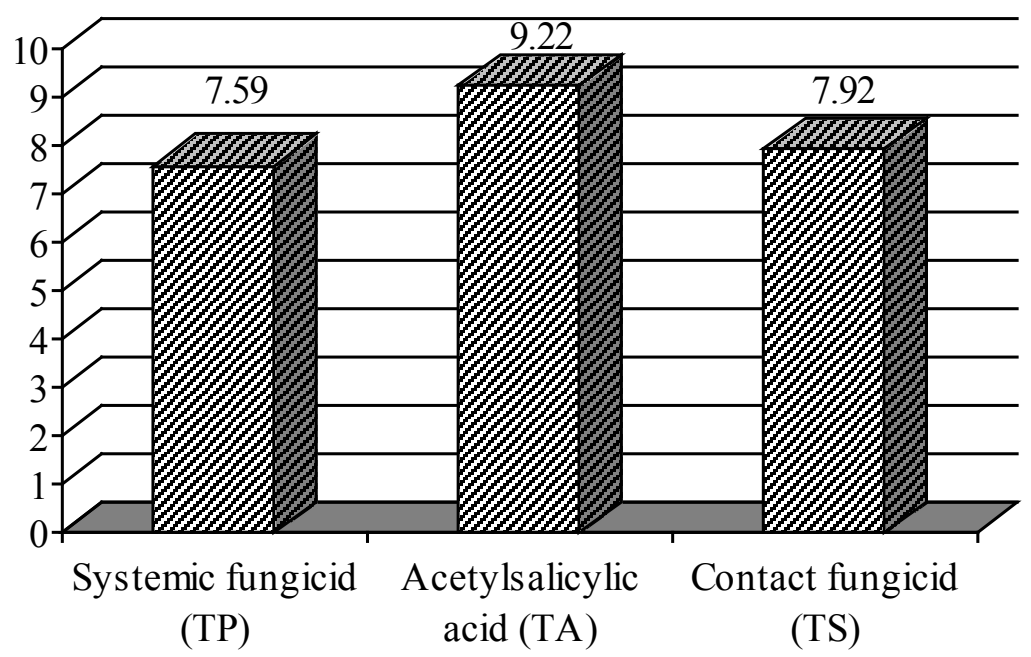

Fig.8. Treatment influence on total production of tomatoes (period of July-October 2013), $\mathrm{kg} / \mathrm{m}^{2}$

Tab.1. The combined influence of cultivar and the way the treatment was performed on tomato production, location Sibiu, year of 2013

\begin{tabular}{|c|c|c|c|c|c|c|c|c|c|}
\hline \multicolumn{2}{|c|}{ Variant } & \multicolumn{4}{|c|}{ Early production } & \multicolumn{4}{|c|}{ Total production } \\
\hline Cultivar & Treatment & $\mathrm{Kg} / \mathrm{m}^{2}$ & $\%$ & $\begin{array}{c}\text { Dif. } \\
\left(\mathrm{kg} / \mathrm{m}^{2}\right)\end{array}$ & Semnif. & $\mathrm{Kg} / \mathrm{m}^{2}$ & $\%$ & $\begin{array}{c}\text { Dif. } \\
\left(\mathrm{kg} / \mathrm{m}^{2}\right)\end{array}$ & Semnif. \\
\hline Buzău 50 & $\mathrm{TA}$ & 3.24 & 100.0 & - & - & 10.21 & 100.0 & - & - \\
\hline Local pop. & $\mathrm{TA}$ & 2.30 & 70.9 & -0.94 & 00 & 8.22 & 80.5 & -1.99 & 00 \\
\hline Buzău 50 & $\mathrm{TP}$ & 2.01 & 100.0 & - & - & 7.66 & 100.0 & - & - \\
\hline Local pop. & $\mathrm{TP}$ & 2.00 & 99.7 & -0.01 & - & 7.53 & 98.3 & -0.13 & - \\
\hline Buzău 50 & TS & 2.66 & 100.0 & - & - & 8.53 & 100.0 & - & - \\
\hline Local pop. & TS & 2.23 & 83.8 & -0.43 & 00 & 7.31 & 85.7 & -1.22 & 00 \\
\hline$\overline{\mathrm{DL}}(\mathrm{p} 5 \%)$ & & & & 0.34 & & & & 0. & \\
\hline $\mathrm{DL}(\mathrm{p} 1 \%)$ & & & & 0.77 & & & & 1.2 & \\
\hline $\mathrm{DL}(\mathrm{p} 0.1 \%)$ & & & & 0.96 & & & & 2. & \\
\hline
\end{tabular}


Analyzing the combined influence of cultivar and treatment application it was found that both varieties have achieved higher early production when performing treatments with acetylsalicylic acid: 3.24 $\mathrm{kg} / \mathrm{m}^{2}$ to the variety Buzău 50 and $2.30 \mathrm{~kg} / \mathrm{m}^{2}$ to the local Sibiu population.

The local Sibiu population used in the experiment compared to the variety of Buzau 50 achieved lower productions to treatment with acetylsalicylic acid and contact fungicides - Bordeaux mixture, the production differences being significant (Tab.1). These results are valid for both early and total production. To acetylsalicylic acid treatment total production was $10.21 \mathrm{~kg} / \mathrm{m}^{2}$ for the variety Buzău 50 and $8.22 \mathrm{~kg} /$ $\mathrm{m}^{2}$ to local population (Tab.1).

Data analysis regarding the combined influence of the products used for combating the diseases of the two varieties showed that regardless of the product used, early production was higher for the variety of Buzău 50. Significant differences of production were found at tomatoes sprinkled with acetylsalicylic acid solution (TA) to early production, respectively $15 \%$ to the local population and $61.5 \%$ to the variety of Buzău 50 , compared to the control group (TP). Significant differences of early production were also found at tomatoes sprinkled with TS, respectively $32 \%$, compared to the control group.

Acetylsalicylic acid treatment of plants ensures $9.2 \%$ total production increases to the local population and $33.3 \%$ to the variety of Buzău 50 , production difference being highly significant compared to the control group. Significant production differences were also found following the treatments with contact fungicides - Bordeaux mixture, but only to the Buzău 50 varieties with an increase of $11.3 \%$ compared to TP.

\section{CONCLUSIONS}

Variety Buzau-50 has better dynamics than the local population of Sibiu. Systemic fungicides treatments have influenced the growth parameters depending on cultivar, accelerate height growth of the tomato variety Buzău-50 after 60 days from planting them in the ground, then it slows down. Contact fungicides - Bordeaux mixture causes the highest number of flowers in inflorescences to the variety Buzău-50. Both chemical treatments cause an irregular growth rhythm of the leaves - 60 days after planting was slow, then sharply accelerated. Acetylsalicylic acid solution and sustainable treatment cause a slower flowering to tomatoes from the local population and the highest number of flowers in inflorescences. Also, these treatments cause an insignificant lower number of fruits to local population tomatoes, but the average diameter of the fruits was higher compared with that treated with pesticides. This resulted in significant increase of early and total production. Both varieties of tomato production were higher in the case of treatment with acetylsalicylic acid solution.

Acknowledgements. This paper was published under the frame of European Social Fund, Human Resources Development Operational Programme 2007-2013, project no. POSDRU/159/1.5/ S/132765.

\section{REFERENCES}

1. Ciofu R, Stan N, Popescu V, Chilom p, Apahidean S, Horgoș A, Berar V, Lauer KF, Atanasiu N (2004). Vegetable Treaty, Ed.Ceres, Bucureşti.

2. Horotan A, Oancea S (2013). Effects of fungicide and acetylsalicylic acid treatments on the physiological and enzymatic activity in tomato (Lycopersicon esculentum Mill.), Acta Universitatis Cibiniensis Series E: Food Technology, vol. 17: $13-26$.

3. Indrea D, Apahidean S Al, Apahidean M, Măniuțiu D, Sima R (2012). Vegetable culture, Ed. Ceres, Bucureşti.

4. Jahanshir A, Dzhalilov F S (2010). The effects of fungicides on Fusarium Oxysporum F. Sp. Lycopersici associated with fusarium wilt of tomato, Journal of Plant Protection research, vol. 50(2): 172 - 178.

5. Pârvu C (1991). Small encyclopedia. The plant Universe, Ed. Enciclopedică, Bucureşti.

6. Praveen KC, Abhilasha A L and Simon S (2013). Effect of certain fungicides and botanicals against early blight of tomato caused by Alternaria solani (Ellis and Martin) under Allahabad Uttar Pradesh, India conditions, International Journal of Agricultural Science and Research, vol. 3 (3): 151 - 156.

7. Sonmez S, Kaplan M, Sonmez NK, Kaya H, Uz I (2006). High level of copper application to soi land leaves reduce the growth and yield of tomato plants, Scientia Agricola, vol. 63(3): 213 - 218.

8. Suciu Z, Pleșca T, Goian M (1987). The vegetable culture in garden, greenhouse and solar, Ed. Facla, Timişoara.

9. Tort N, Öztürk I and Güvensen A(2005). Effect of some fungicides on pollen morphology and anatomy of tomato, Pakistan Journal of Botany, 37(1), 23-30.

10. Wilson SV, Marco Antonio TR, Edson Be, de Souza NL (2003). Physiological effects of Strobilurin fungicides 
on plants, Publicatio UEPG: Ciencias Exatas e da Terra, Ciencias Agrarias e Engenharias, vol. 9(3): 59 - 68.

11. *** www.istis.ro, State Institute for Variety Testing and Registration: Official Catalogue of
12. varieties of crop plants in Romania (Catalogul oficial al soiurilor de plante de cultura din

13. România) (2012);

14. *** http://en.wikipedia.org/wiki. 